\title{
WISATA REKREASI AIR DAN KEBUGARAN DI ANCOL
}

\author{
Irene Melisa ${ }^{1)}$, Rudy Surya ${ }^{2)}$ \\ 1) Program Studi S1 Arsitektur, Fakultas Teknik, Universitas Tarumanagara, irene.melisa.10@gmail.com \\ 2) Program Studi S1 Arsitektur, Fakultas Teknik, Universitas Tarumanagara, rudys@ftuntar.ac.id
}

\begin{abstract}
Abstrak
Tingkat stress yang tinggi di Jakarta membuat kebutuhan akan rekreasi meningkat. Proyek ini memiliki tujuan untuk mewadahi olahraga air di Ancol sekaligus menjadi tempat wisata baru bagi kota Jakarta. Metode yang digunakan adalah deksriptif dimana dilakukan pengamatan langsung di lapangan dan analisis data - data untuk menentukan kebutuhan ruang hingga didapatkan hubungan ruang serta sirkulasi di dalam tapak. Konsep yang digunakan adalah Shelter - Inside out dimana bangunan yang terletak pinggir pantai bisa mengakomodasi orang - orang yang ingin bermain olahraga air tanpa menghilangkan esensi dari wisata pantai nya itu sendiri. Sehingga bangunan di desain memilik ruang dalam yang bersifat semi terbuka dan selalu mendapatkan view ke laut. Selain itu, bangunan juga bersifat sebagai shelter untuk melindungi dari panas dan teriknya matahari. Kelompok kegiatan dibuat berdasarkan zoning dan memperhatikan privasi dari tiap kegiatan. Olahraga air yang diwadahi adalah perahu dayung, jet ski, perahu layar, dan canoe. Dengan adanya bangunan ini diharapkan dapat menghidupkan kawasan dan menarik pengunjung untuk datang.
\end{abstract}

Kata kunci: Jakarta, olahraga air, pantai, rekreasi, wisata

\begin{abstract}
High level of stress in Jakarta increase the need for recreation. This project's aim is to accommodate water sports in Ancol as well as becoming a new tourist spot for Jakarta. The method used is descriptive which is done by direct observation in the field and data analysis to determine the space requirements to obtain the space relation and circulation in the site. The concept used is Shelter - Inside out where the building that is located on the beach can accommodate people who want to play water sports without losing the essence of the beach tourism itself. So the building is designed with a semi-open space and every part will always get a view to the sea. In addition, the building is also a shelter to protect from the heat of the sun. Activities are grouped based on zoning and paying attention to the privacy of each activity. Water sports that are accommodated are rowing boats, jet skis, sailboats, and canoe. The existence of this building is expected to be able to revive the area and attract more visitors to come.
\end{abstract}

Keywords beach, Jakarta, recreation, tourism, water sports

\section{PENDAHULUAN \\ Latar Belakang}

Perusahaan asal Inggris Zipjet merilis hasil survei peringkat kota dengan tingkat stres paling tinggi di Asia tahun 2017. Hasilnya, Kota Jakarta menempati posisi keenam dari 150 kota di dunia dalam daftar tersebut. Dalam sebuah wawancara di Metro TV, Psikolog Klinis Ratih Ibrahim menyebutkan bahwa stres merupakan hal lumrah yang bisa terjadi kapan saja dalam hidup manusia. Berkaca dari hasil survei tersebut secara umum stres memang biasa terjadi di kota kota besar. Pertanyaan berikutnya adalah bagaimana cara meredakan tingkat stress yang terlalu tinggi?

Menurut Kerri-Ann Jennings, MS, RD, seorang pakar terapi, ada 16 cara dalam mengatasi stress dan khawatir yang berlebihan, diantaranya adalah berolahraga, menghabiskan waktu bersama 
teman dan keluarga, serta mengikuti kelas yoga ${ }^{1}$. Dalam konteks kota, wisata yang dibentuk harus bisa menjawab kebutuhan tersebut. Karena itulah diusulkan program wisata Wellness and Recreation Center dengan beberapa program utama dan pendukungnya. Diharapkan program yang diusulkan bisa menjadi tempat "pelarian" warga Jakarta untuk meredakan stress, berolahraga, dan memberikan hiburan serta rekreasi ditengah keadaan kota Jakarta yang sangat padat. Namun, tapak menjadi salah satu poin penting dalam proyek ini karena berhubungan dengan rekreasi yang akan dibentuk.

Pada bulan Mei tahun 2018, PT Pembangunan Jaya Ancol Tbk (PJAA) menandatangi perjanjian kerja sama dengan Crown Group, perusahaan yang berbasis di Sydney dalam pembangunan hunian vertikal mewah di kawasan Ancol senilai 7 triliun rupiah ${ }^{2}$. Selain itu, kawasan tepi pantai (waterfront) Ancol akan dikembangkan lebih lagi. Hal ini merupakan potensi pariwisata yang sangat baik dalam konteks kota Jakarta. Didukung dengan kebutuhan masyarakat akan daerah wisata rekreasi dan kesehatan, maka Ancol Welness and Water Recreation menjadi proyek yang akan dibuat.

Pilihan olahraga yang terdapat di tempat rekreasi ini lebih mengarah pada jenis olahraga yang belum banyak di wadahi di Jakarta walaupun sudah menjadi salah satu cabang dari ASEAN Games 2018. Contohnya adalah olaharaga sailing, jetski dan canoe. Dengan pengembangan waterfront sebagai basis dari wisata dan olahraga ini, diharapkan kasawan Ancol bisa menjadi daya tarik wisata di kota Jakarta.

\section{Susunan Penulisan}

Terdiri dari Pendahuluan, Metode Penelitian, Hasil Penelitian dan analisis, Kesimpulan dan Saran, serta bibliografi.

\section{METODE}

Menurut data.jakarta.go.id, Taman Impian Jaya Ancol adalah salah satu destinasi wisata unggulan yang mempunyai daya tarik di kota Jakarta. Dengan berbagai pilihan prgoram wisata seperti wisata themepark, rekreasi air, dan kuliner, daerah waterfront bisa dikembangkan lebih lagi untuk menjadi wisata publik yang memiliki potensi menarik wisatawan baik dari dalam negri hingga luar negri.

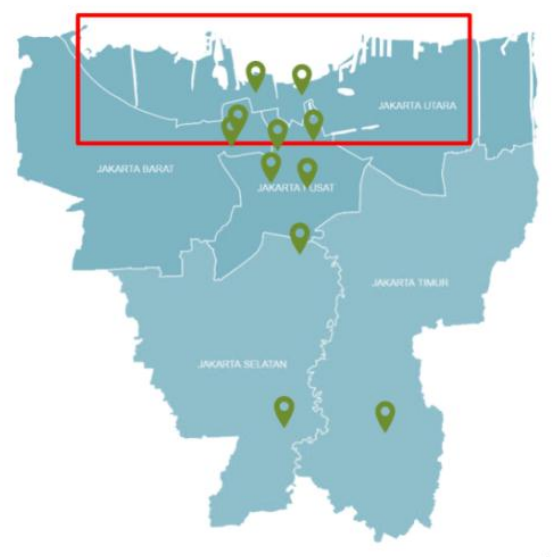

Gambar 1. Persebaran Potensi Daya Tarik Wisata Unggulan Provinsi DKI Jakarta Sumber: http://gis.bpbd.jakarta.go.id/layers/geonode\%3Adki_kota

\footnotetext{
${ }^{1}$ Kerri - Ann Jennings, "16 Simple Ways to Relieve Stress and Anxiety", Helathline.com, diakses dari https://www.healthline.com/nutrition/16-ways-relieve-stress-anxiety, pada tanggal 13 Juli 2018 pukul 1:45 ${ }^{2}$ https://industri.kontan.co.id/news/crown-group-dan-jaya-ancol-bangun-properti-water-front-rp-7-triliun, diakses pada 5 September 2018
} 
Setelah menentukan area waterfront sebagai wisata yang dipilih yaitu lebih tepatnya di daerah Jakarta Utara, daerah waterfront di Jakarta Utara sendiri terdapat beberapa titik yang berpotensi dikembangkan menjadi daerah wisata tepi air, yaitu Pantai Indak Kapuk (PIK), kawasan Pluit, kawasan Tanjung Priok, dan Kawasan Ancol.

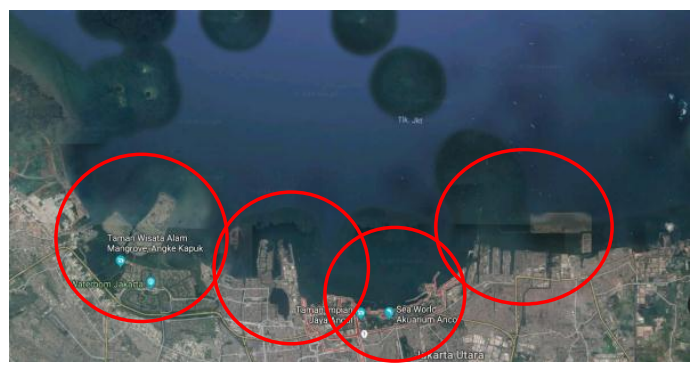

Gambar 2. Analisa Daerah Waterfront Jakarta Sumber: google maps yang diolah kembali

Dari segi wisata, daerah PIK dan Pluit merupakan daerah yang didominasi dengan pemukiman, daerah Tanjung Priok merupakan daerah perdagangan, karena itulah dipilih daerah Ancol yang merupakan daerah wisata untuk dikembangkan lagi menjadi wisata tepi air.

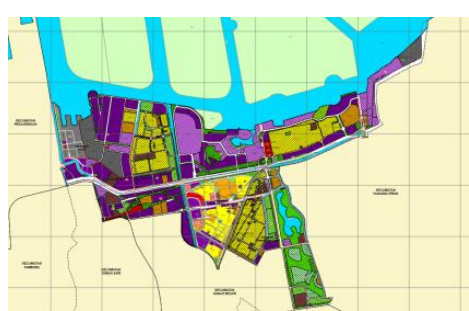

Gambar 3. Peta Zonasi Kecamatan Pademangan Sumber: https://tataruang.jakarta.go.id/

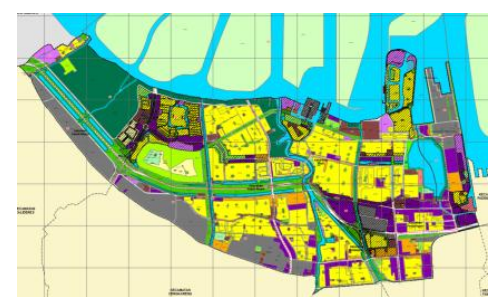

Gambar 4. Peta Zonasi Kecamatan Penjaringan Sumber: https://tataruang.jakarta.go.id/

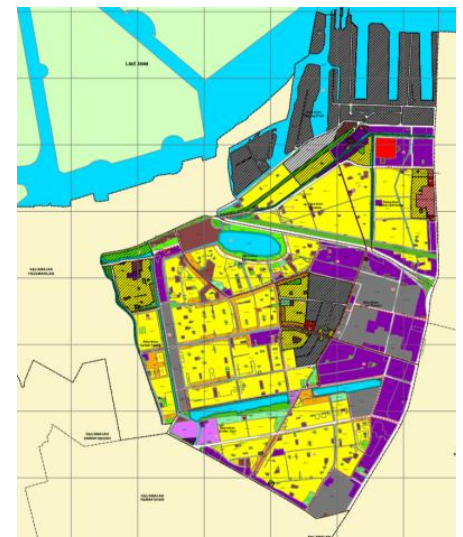

Gambar 5. Peta Zonasi Kecamatan Tanjung Priok Sumber: https://tataruang.jakarta.go.id/ 
Setelah menentukan Kecamatan Pademangan yaitu daerah kawasan Ancol sebagai kawasan terpilih, dianalisa lagi dengaan radius lebih kecil untuk menentukan tapak terpilih.

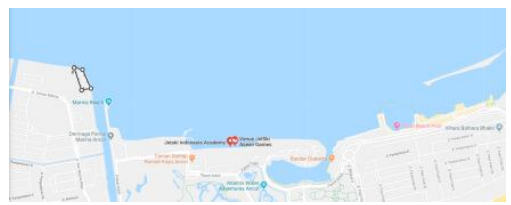

\section{Gambar 6. Alternatif Tapak 1}

Sumber: googlemaps yang diolah kembali

Alternatif tapak pertama terletak di dekat dermaga pantai marina ancol. Tapak berada di zona perdagangan dan terletak di pinggir pantai. Namun karena tapak berada di luar kawasan Taman Impian Jaya Ancol, tapak kurang tepat untuk dijadikan daerah wisata dimana wisatawan akan lebih banyak menuju ke area dengan destinasi yaitu di Taman Impian Jaya Ancol sendiri.

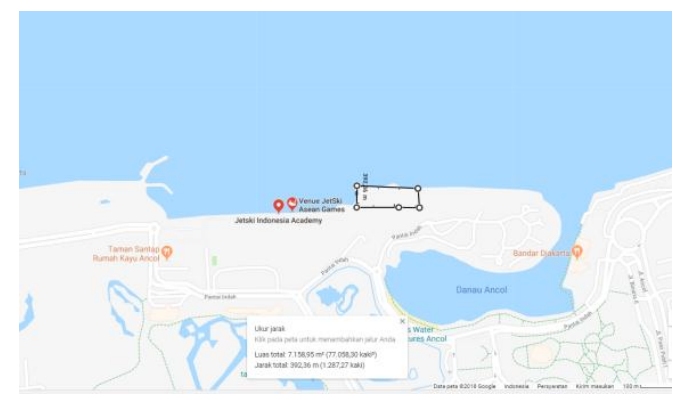

Gambar 7. Alternatif Tapak 2

Sumber: googlemaps yang diolah kembali

Tapak berada di dekat venue jet ski yang baru dibangun dalam rangka asean games 2018. Terletak di zona perkantoran, perdagangan, dan jasa, tapak merupakan alternatif yang tepat karena bisa menghubungkan antara venue dengan pengembangan waterfront di kemudian harinya

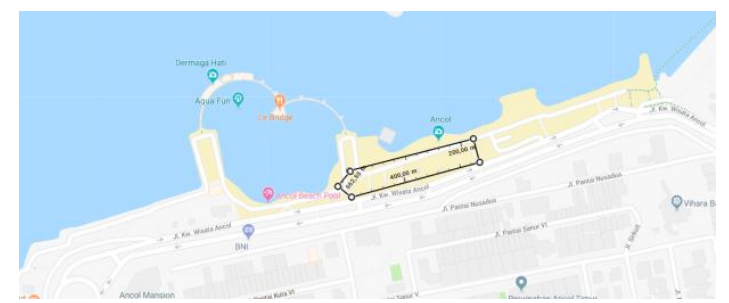

Gambar 8. Alternatif Tapak 3

Sumber: googlemaps yang diolah kembali

Alternatif tapak ke tiga berada tidak jauh dari venue asean games dan juga berdekatan dengan pantai lagoon. Tapak juga berada di zona zona perkantoran, perdagangan, dan jasa KDB rendah. 


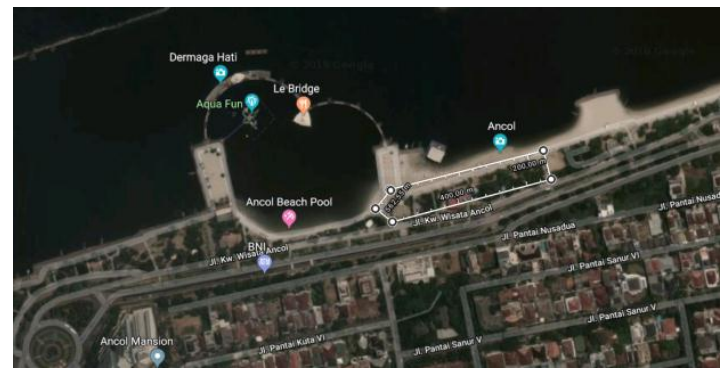

Gambar 9. Tapak terpilih

Sumber: googlemaps yang diolah kembali

Dari ketiga alternatif tapak, dilakukan analisa dan terpilih tapak ke 3 sebagai tapak yang paling tepat. Luas tapak adalah 4.168 m2 dengan KDB 35, KLB 1.2, KB 4, KDH 45, dan KTB 40.

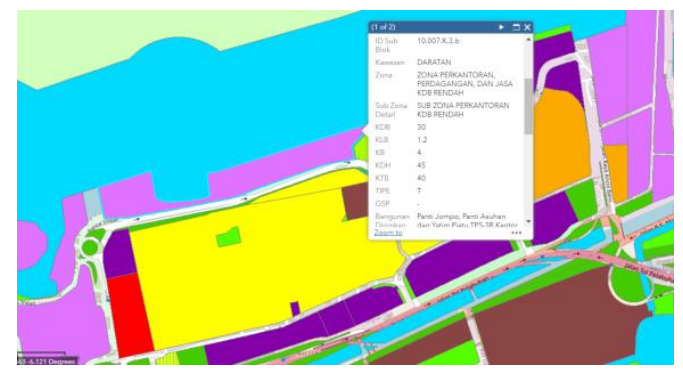

Gambar 10. Peta Zonasi Tapak Terpilih

Sumber: googlemaps yang diolah kembali

Dari segi sirkulasi, tapak dekat dengan jalan utama di dalam kawasan Ancol dan memiliki teluk di bagian area pantai.

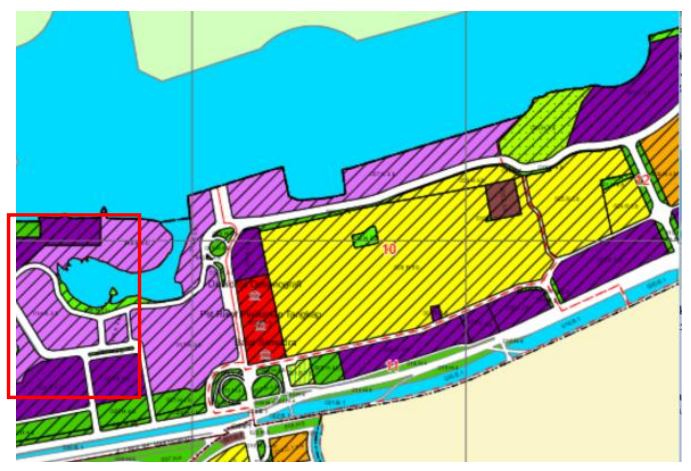

Gambar 11. Peta Zonasi Tapak Terpilih

Sumber: googlemaps yang diolah kembali

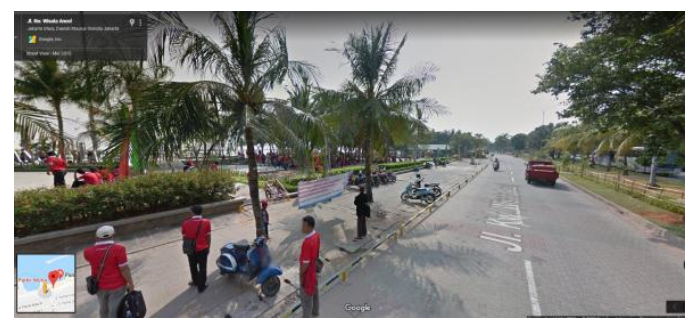

Gambar 12. Kondisi Tapak

Sumber: googlemaps yang diolah kembali

Zonasi tapak akan terbagi menjadi publik dan privat. Zona publik yaitu ruang outdoor area dan restoran diletakan di area sisi tepi air bagian barat yang dekat dengan teluk dan plaza. Sedangkan 
zona privat yaitu galeri, tribun jetski, dan ruang klub diletakan di sisi dekat tepi air bagian timur. Area parkir untuk motor diletakan di pinggir jalan seperti kondisi eksisting di Ancol, parkir mobil bisa menggunakan basement ataupun tempat parkir Bende yang sudah disediakan pihak Ancol berjarak 500 meter dari tapak.

\section{DISKUSI DAN HASIL}

Program yang diusulkan adalah Ancol Welness and Water Recreation yang memiliki tujuan untuk mengembangkan potensi pariwisata di daerah tepi air Ancol sekaligus memperhatikan segi kesehatan dengan olahraga air yang belum banyak diwadahi di Jakarta.

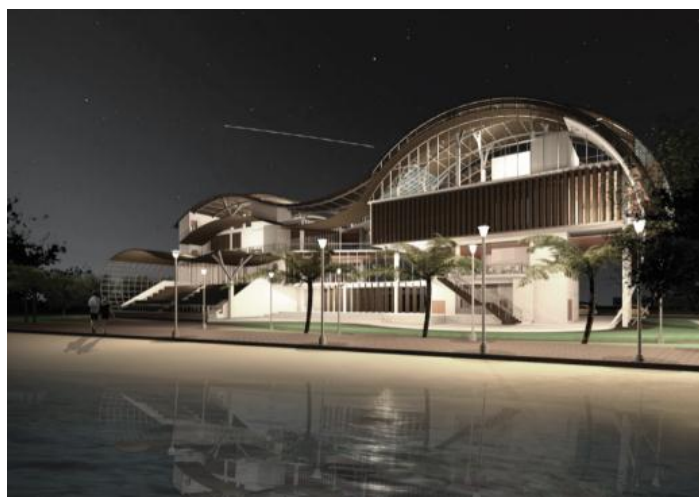

Gambar 13. Perspektif Eksterior

Sumber: googlemaps yang diolah kembali

Program ruang berasal dari hasil studi 5 preseden. Yaitu kombinasi dari fungsi utama dan fungsi pendukung. Konsep yang diusung adalah suatu tempat dimana warga Jakarta bisa datang dan meredakan stress serta mencapai keadaan sehat di tengah - tengah hiruk pikuk kota metropolis.

Tabel 1. Kelompok Kegiatan

\begin{tabular}{|c|c|c|c|}
\hline Jenis Aktivitas & Pelaku & Aktivitas & Kebutuhan Ruang \\
\hline \multicolumn{4}{|c|}{ KELOMPOK KEGIATAN FASILITAS UTAMA } \\
\hline Aktivitas umum & pengunjung & \begin{tabular}{|l} 
•Membeli tiket \\
masuk \\
•Menanyakan \\
informasi tentang \\
fasilitas wisata \\
-Menggunakan \\
fasilitas olahraga air \\
(kayak, dayung, \\
jetski) \\
•Berolahraga dan \\
rekreasi di taman \\
terbuka dan ruang \\
outdoor
\end{tabular} & $\begin{array}{l}\text { - Loket tiket } \\
\text { - Pos informasi } \\
\text { - Dermaga } \\
\text { - Gudang peralatan }\end{array}$ \\
\hline
\end{tabular}

\begin{tabular}{|c|c|c|c|}
\hline & pengelola & Mengelola wisata air & dermaga \\
\hline \multicolumn{4}{|c|}{ KELOMPOK KEGLATAN FASILITAS PENUNJANG } \\
\hline Altivitas penunjang & pengunjung & \begin{tabular}{|l|} 
- Makan dan minum \\
-Berbelanja souvenir \\
-Beristirahat dan \\
menikmati \\
-pemandangan \\
- Menggunakan toilet \\
- Melihat \\
pertunjukkan seni \\
-Anak-anak bermain
\end{tabular} & $\begin{array}{l}\text { - Restoran } \\
\text { - Kios jajanan } \\
\text { - Kios souvenir } \\
\text { - Gazebo } \\
\text { - Mushola } \\
\text { - Toilet } \\
\text { - Playground }\end{array}$ \\
\hline & pengelola & $\begin{array}{l}\text { - Menjual makanan } \\
\text { dan minuman } \\
\text { - Menjual souvenir } \\
\text { - Beribadah } \\
\text { - Menggunakan toilet }\end{array}$ & $\begin{array}{l}\text { - Kios jajanan } \\
\text { - Kios souvenir } \\
\text { - Mushola } \\
\text { - Toilet }\end{array}$ \\
\hline
\end{tabular}




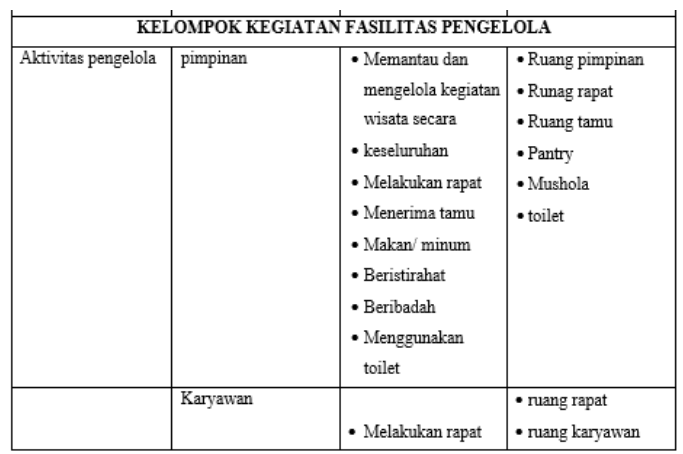

Sumber: Olahan Pribadi

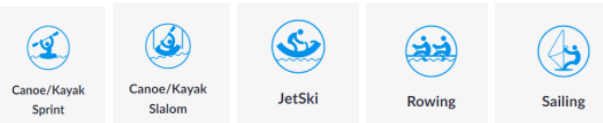

Gambar 13. Jenis Olahraga Air Terpilih Sumber: https://asiangames2018.id

Berdasarkan studi preseden, didapatkan program - program utama yang ingin diusulkan yaitu, wisata olahraga air (canoe, jetski, dayung, dan perahu layar). Ruang pendukung untuk olahraga air adalah ruang ganti, ruang bilas, tribun jetski, dan area tiket. Sedangkan untuk program lain nya adalah ruang multifungsi, area makan indoor, area makan semi - outdoor, taman terbuka, spa, dan yoga. Program pendukung dibuat untuk mewadahi enam dimensi wellness.

Berdasarkan analisa dan hasil desain maka didapatkan luas lantai dasar $1.173 \mathrm{~m}^{2}$, lantai dua $1.252 \mathrm{~m}^{2}$, lantai tiga $1.153 \mathrm{~m}^{2}$, lantai empat $1.054 \mathrm{~m}^{2}$, luasan total $4.162 \mathrm{~m}^{2}$ dan basement 1.637 $\mathrm{m}^{2}$ dengan detail program ruang sebagai berikut :

Tabel 2. Program Ruang

\begin{tabular}{|lll|}
\hline Level & NAMA RUANG & LUAS \\
& LOBBY & $228 \mathrm{~m}^{2}$ \\
\hline & EXHIBITION SPACE & $113 \mathrm{~m}^{2}$ \\
\hline & GUDANG PERALATAN & \\
& OLAHRAGA AIR & $94 \mathrm{~m}^{2}$ \\
\hline KAMAR BILAS & $86 \mathrm{~m}^{2}$ \\
\hline SIRKULASI VERTIKAL & $12 \mathrm{~m}^{2}$ \\
\hline \multirow{3}{*}{ LANTAI 1 } & GUDANG PERALATAN & $47 \mathrm{~m}^{2}$ \\
\hline & TEMPAT PENYEWAAN ALAT & $11 \mathrm{~m}^{2}$ \\
\hline & LITE BITE FOOD KIOSK & $20 \mathrm{~m}^{2}$ \\
\hline & GUDANG & $5 \mathrm{~m}^{2}$ \\
\hline & TOILET & $14 \mathrm{~m}^{2}$ \\
\hline & SIRKULASI VERTIKAL & $21 \mathrm{~m}^{2}$ \\
\hline JANITOR & $2 \mathrm{~m}^{2}$ \\
\hline LOBBY & $24 \mathrm{~m}^{2}$ \\
\hline KANTOR PENGELOLA & $41 \mathrm{~m}^{2}$ \\
\hline RESEPSIONIS & $15 \mathrm{~m}^{2}$ \\
\hline LOUNGE & $126 \mathrm{~m}^{2}$ \\
\hline OUTDOOR PICNIC AREA & $311 \mathrm{~m}^{2}$ \\
\hline & $1173 \mathrm{~m}^{2}$ \\
\hline
\end{tabular}




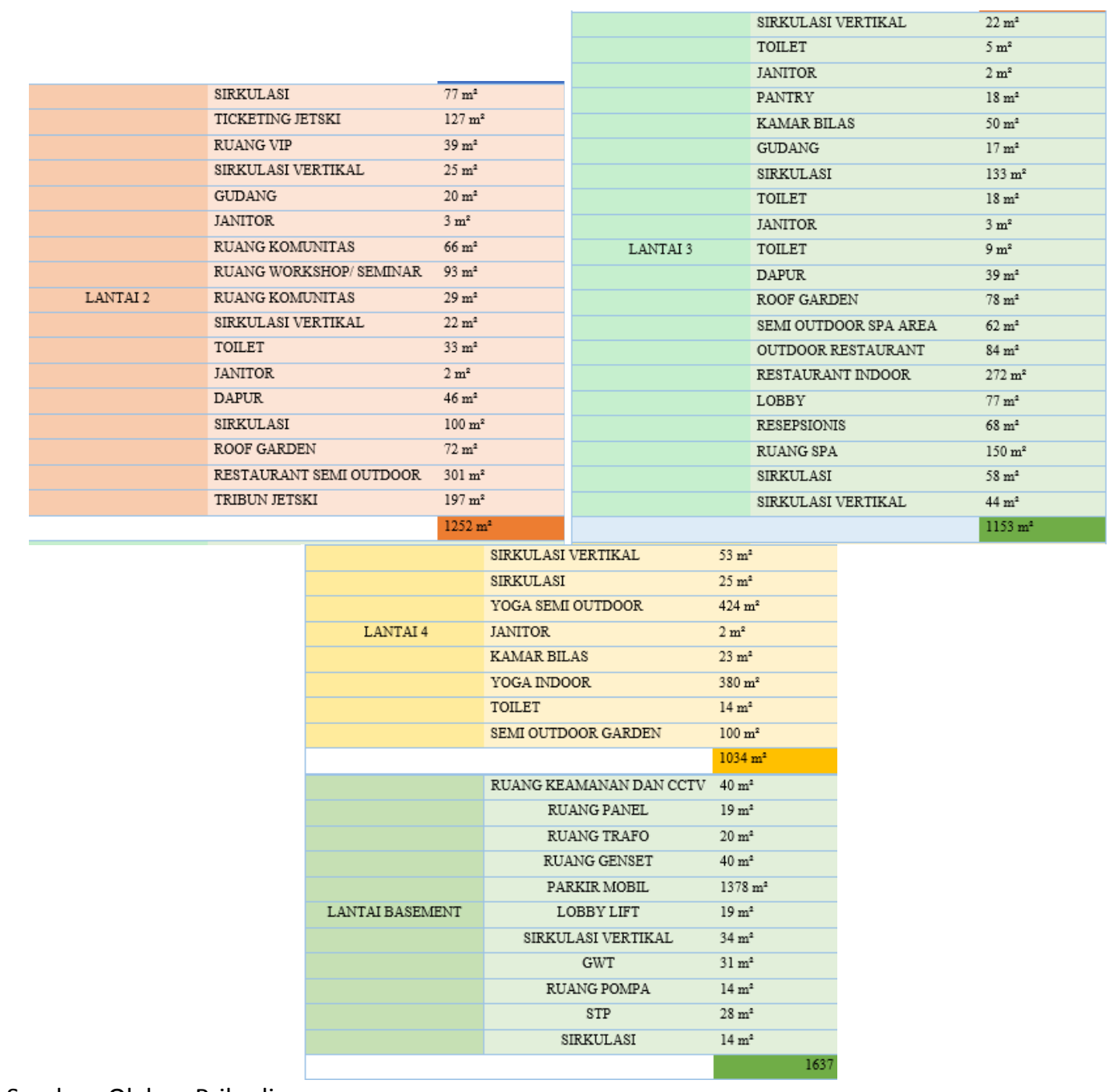

Sumber: Olahan Pribadi

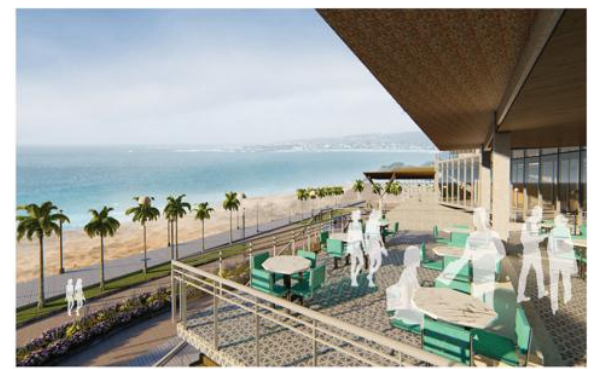

Gambar 15. Perspektif Restoran Sumber: https://asiangames2018.id

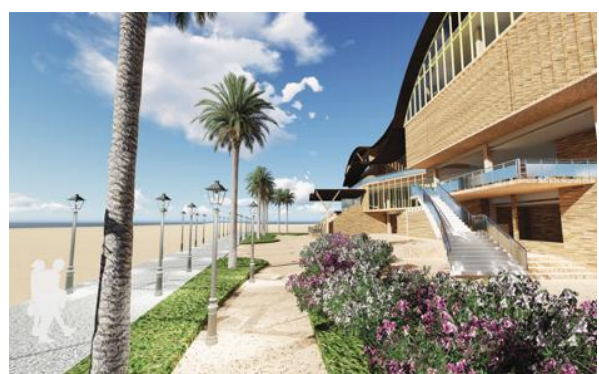

Gambar 16. Perspektif Ruang Luar

Sumber: https://asiangames2018.id 
Ruang luar yang terbentuk di desain untuk terhubung dengan pantai publik yang ada. Selain itu dibuat juga tangga dari lantai dasar langsung ke lantai dua sebagai akses dan penghubung dengan plaza yang terletak di sebelah tapak.

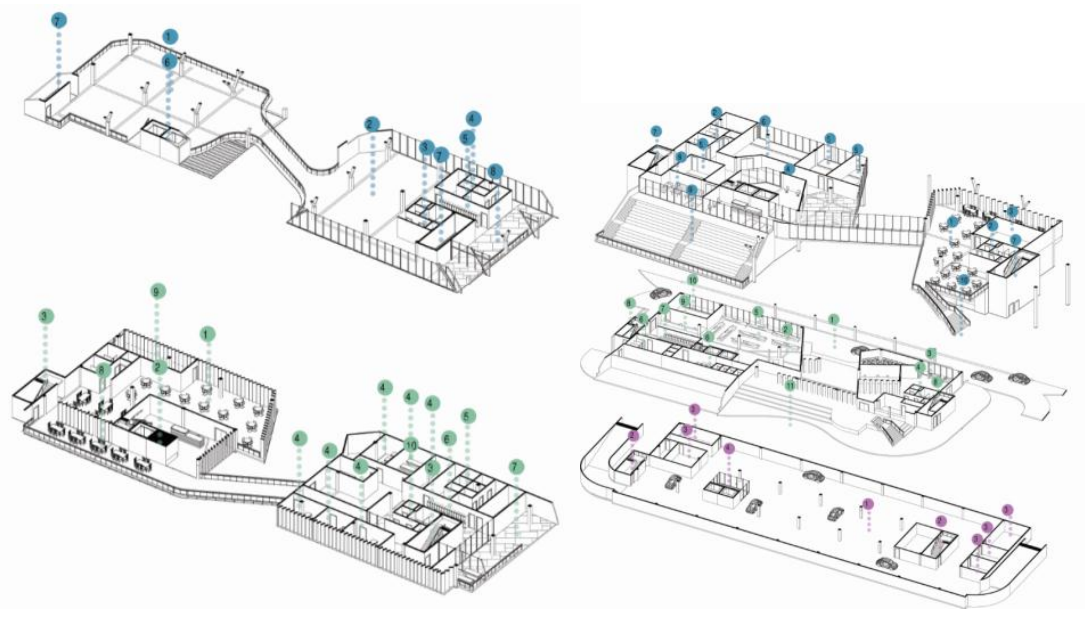

Gambar 17. Denah

Sumber: https://asiangames2018.id

Struktur atap yang digunakan adalah Glued Laminated Timber atau bisa disebut juga Glulam. Material ini dipilih karena pertimbangan daerah pantai dengan tingkat korosi tinggi untuk bahan rangka atap besi/ baja. Sedangkan material glulam ini terbuat dari bahan partikel kayu yang dipadatkan dan bisa dibentuk sesuai keinginan dengan bentang lebar tanpa perlu struktur kolom penyangga. Selain bisa berbentuk lengkung, glulam ini juga jauh lebih ringan dari rangka baja/besi dan pemasangan juga lebih mudah.

\section{KESIMPULAN DAN SARAN}

Setelah melakukan analisa dan proses desain maka didapatkan disimpulkan wisata dalam konteks ruang di Jakarta memiliki banyak potensi yang bisa dikembangkan. Salah satu yang memiliki potensi besar adalah daerah waterfront atau tepi pantai Jakarta yaitu di bagian Ancol, Jakarta Utara. Jika dikaitkan dengan kebutuhan masyarakat akan tempat rekreasi serta kebugaran, maka proyek Ancol Wellness and Water recreation menjadi proyek yang tepat untuk dikembangkan. Dari analisis tapak dan kebutuhan ruang didapatkan bentuk bangunan serta sirkulasi dalam tapak yang lebih bersifat terbuka dan memiliki banyak ruang semi - outdoor karena bangunan bersifat publik namun tetap memiliki ruang private. Dengan adanya bangunan ini yang memiliki konsep shelter inside out untuk mewadahi masyarakat maka diharapkan bidang pariwisata dan daerah tepi air di Ancol bisa berkembang lebih lagi. Digunakan material atap glued laminated timber untuk menyesuaikan daerah tapak yang berdekatan dengan laut dan mendapatkan bentuk melengkung dengan struktur bentang lebar.

\section{REFERENSI}

Breen, Ann; Rigby, Dick. (1994). Waterfronts - Cities Reclaim Their Edge. Amerika: Kim Hupp Lee. Baud-bovy, Manuel \& Fred Lawson. (1997). Tourism and Recreation Development : A Handbook of Physical Planning. Great Britain : The Architectural Press Ltd.

De Chiara, Joseph; J Crosbie, Michael. (2001). Time Saver Standards for Building Types.Singapore :McGraw Hill Book Companies Inc. Echols.

J.M. dan Shadily, H. (2005). Kamus Inggris Indonesia : An English - Indonesian Dictionary. PT Gramedia, Jakarta. 
Lee, Uje. (2010). Waterfront; Resewing the City Plaza and Square in Europe. Korea: Art Data. Specht, Jan. (2014). Architectural Tourism. Belanda : Springler Gabler.

Torre, L. A. (1989). Waterfront development. New York: Van Nostrand Reinhold Wren, Douglas M. (1983). Urban Waterfront Development. Urban Land Institue: Washington D.C https://www.healthline.com/nutrition/16-ways-relieve-stress-anxiety\#section1 (Diakses tanggal 13 Juli 2018 pukul 3:11)

https://www.medcom.id/rona/kesehatan/ybDMMMjk-Jakarta-dinobatkan-salah-satu-kotadengan-tingkat-stres-tinggi-psikolog-itu-lumrah (Diakses tanggal 29 Juli 2018 pukul 19:00) https://databoks.katadata.co.id/datapublish/2017/01/27/penduduk-dki-Jakarta-didominasiumur-25-34-tahun ( Diakses tanggal 16 Juli 2018 pukul 3:14) https://www.nationalwellness.org/? (Diakses tanggal 29 Juli 2018 pukul 7:04) http://tataruang.atr-bpn.go.id/Bulletin/index.asp?mod=_fullart\&idart=218 (Diakses tanggal 7 September 2018 pukul 2:54) 